
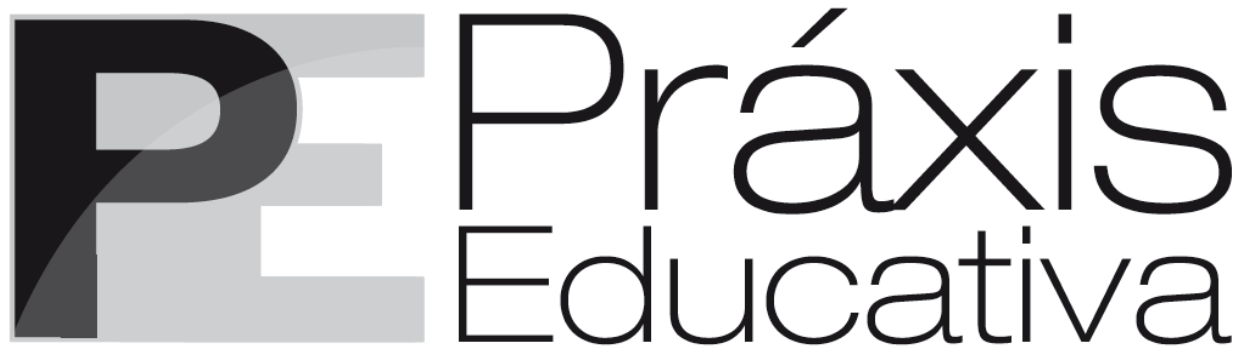

ISSN 1809-4031

elSSN 1809-4309

https://doi.org/10.5212/PraxEduc.v.16.15213.006

\title{
Ética na pesquisa em Psicologia e Educação em Portugal: contributos para pensar o caso brasileiro*
}

\section{Ethics in Psychology and Education research in Portugal: contributions to think about the Brazilian case}

\section{Ética en la investigación en Psicología y Educación en Portugal: contribuciones para pensar el caso brasileño}

Pedro Savi Neto ${ }^{* *}$

iD https://orcid.org/0000-0001-8781-5277

Mónica de la Fare ${ }^{* * *}$

iD https:/ / orcid.org/0000-0002-2660-4043

Inês Nascimento ${ }^{* * * *}$

iD https://orcid.org/0000-0003-2063-1697

Resumo: Este artigo apresenta um estudo sobre o modelo português de regulação da conduta em pesquisa nas áreas de Educação e Psicologia com a finalidade de contribuir para o debate brasileiro sobre esse tema. Com relação ao método, trata-se de uma pesquisa exploratória com abordagem quanti-qualitativa, baseada na análise documental combinada com a análise hermenêutica objetiva de dados coletados por meio da técnica do survey, utilizada para o levantamento de opiniões de doutorandos em Educação e em Psicologia de Portugal. É possível apontar como principais conclusões do estudo: (1) a semelhança entre os dois modelos no tocante a um enfrentamento majoritariamente normativo da questão ética em pesquisa; e (2) o caráter mais descentralizado do modelo português, que combina orientações gerais transnacionais com

\footnotetext{
* Este trabalho foi realizado com apoio da Coordenação de Aperfeiçoamento de Pessoal Nível Superior-Brasil (Capes) - Código de Financiamento 001, com bolsa do Programa Nacional de Pós-Doutorado (PNPD) para Pedro Savi Neto.

** Doutor em Educação, Bolsista do Programa Nacional de Pós-Doutorado (PNPD) - Capes e Professor Colaborador do Programa de Pós-Graduação em Educação da Pontifícia Universidade Católica do Rio Grande do Sul, Escola de Humanidades (PUC/RS). E-mail: <pedro.savi@pucrs.br>.

*** Doutora em Serviço Social, Professora do Programa de Pós-Graduação em Educação da Pontifícia Universidade Católica do Rio Grande do Sul, Escola de Humanidades (PUCRS). E-mail: <monica.fare@pucrs.br>.

**** Doutora em Psicologia, Professora da Faculdade de Psicologia e Ciências da Educação da Universidade do Porto, Portugal. E-mail: <ines@fpce.up.pt>.
} 
normativas setoriais e nacionais, de forma a contemplar uma maior participação das Universidades, das associações representativas das diferentes áreas e dos próprios pesquisadores.

Palavras-chave: Ética na pesquisa. Regulação. Psicologia e Educação. Portugal e Brasil.

\begin{abstract}
This article presents a study on the Portuguese model of conduct regulation in research in the areas of Education and Psychology in order to contribute to the Brazilian debate on this topic. Regarding the method, it is an exploratory research with a quantitative and qualitative approach, based on documentary analysis combined with the objective hermeneutic analysis of data collected through the survey technique, used to survey the opinions of doctoral students in Education and in Psychology from Portugal. It is possible to point out as the main conclusions of the study: (1) the similarity between the two models regarding a mostly normative confrontation of the ethical question in research; and (2) the more decentralized character of the Portuguese model, which combines general transnational guidelines with normative sectoral and national ones, with greater participation of Universities, associations representing different areas and researchers themselves.
\end{abstract}

Keywords: Ethics in research. Regulation. Psychology and Education. Portugal and Brazil.

Resumen: Este artículo presenta un estudio sobre el modelo portugués de regulación de la conducta en investigación en las áreas de Educación y Psicología, con la finalidad de contribuir para el debate brasileño sobre ese tema. En relación al método, se trata de una investigación exploratoria con abordaje cuanticualitativo, basado en el análisis documental combinado con el análisis hermenéutico objetivo de datos colectados por medio de la técnica survey, utilizada para el mapeamento de opiniones de doctorandos en Educación y en Psicología de Portugal. Es posible señalar, como principales conclusiones del estudio, (1) la semejanza entre los dos modelos en lo que se refiere al enfrentamiento mayoritariamente normativo de la cuestión ética en investigación y (2) el carácter más descentralizado del modelo portugués, que combina orientaciones generales transnacionales con normativas sectoriales y nacionales, que combina orientaciones generales trasnacionales de forma a contemplar una mayor participación de las universidades, de las asociaciones representativas de diferentes áreas y de los propios investigadores.

Palabras claves: Ética en la investigación. Regulación. Psicología y Educación. Portugal y Brasil.

\title{
Introdução
}

O presente artigo faz parte de um conjunto de pesquisas iniciadas em 2016 no campo da Educação brasileiro, motivadas pelas reações de pesquisadores e das respectivas entidades representativas das áreas das Ciências Humanas e Sociais (CHS) sobre a inadequação (tanto na forma quanto no conteúdo ${ }^{1}$ ) da Resolução do Conselho Nacional de Saúde (CNS) No 466, de 12 de dezembro de 2012 (BRASIL, 2013), que consagra, no Brasil, o modelo biomédico de normatização (DE LA FARE; CARVALHO; PEREIRA, 2017). Tal Resolução substituiu a Resolução CNS No 196, de 10 de outubro de 1996 (BRASIL, 1996), normativa pela qual foi criado o sistema de regulação nacional. Esse sistema, denominado CEP/CONEP, é integrado pela Comissão Nacional de Ética em Pesquisa (CONEP) do CNS, com a qual se articulam os Comitês de Ética em Pesquisa (CEPs) das Instituições de Ensino Superior. Em 2016, A Resolução CNS N ${ }^{\circ}$ 510, de 7 de abril de 2016, decorrente das Resoluções retromencionadas, foi aprovada como marco regulatório específico para as CHS (BRASIL, 2016).

\footnotetext{
${ }^{1}$ Um panorama das condições de aprovação da Resolução CNS No 510, de 7 de abril de 2016, que atualmente regula as CHS, pode ser consultado em: Duarte (2015, 2017), Edler (2015), Sarti (2015), Santos e Jeolás (2015), Sobotkka (2015) e Zaluar (2015), referidos às CHS em geral; e, especificamente para a área da Educação, ver Mainardes (2014, 2016, 2017), de La Fare e Savi Neto (2019), Savi Neto e de la Fare (2019) e Savi Neto, de la Fare, Silva (2020). Para produções anteriores à aprovação dessa Resolução, ver Carvalho e Machado (2014) e o livro organizado por Santos e Karnopp (2017). A Associação Nacional de Pós-Graduação e Pesquisa em Educação - ANPEd (2019) disponibiliza na página web institucional uma seção dedicada ao tema Ética na Pesquisa, na qual se apresenta uma ampla lista de artigos sobre esse tema, alguns deles citados neste artigo.
}

Práxis Educativa, Ponta Grossa, v. 16, e2115213, p. 1-20, 2021 Disponível em: <https://www.revistas2.uepg.br/index.php/praxiseducativa> 
A problemática nacional está inserida em um contexto internacional marcado por um intenso movimento de regulação da conduta em pesquisa nas $\mathrm{CHS}^{2}$ levado a efeito a partir do paradigma biomédico (ISRAEL; HAY, 2006; RORIZ; PADEZ, 2017). Neste estudo, com a finalidade de oxigenar o debate brasileiro a partir de uma perspectiva externa, serão apresentados argumentos provenientes do modelo português de regulação da conduta em pesquisa nas CHS, especialmente dos campos da Educação e da Psicologia. Nesse sentido, registra-se que as pesquisas anteriores foram realizadas no campo brasileiro da Educação; contudo, devido à proximidade histórica entre os campos da Psicologia e da Educação em Portugal ${ }^{3}$, que ainda é preservada em nível de organização de algumas universidades, optou-se pela análise combinada das duas áreas neste estudo, o que favoreceu a coleta dos dados e permitiu a formação de uma amostra mais expressiva.

Apesar das características nacionais particulares da regulação da conduta em pesquisa nas CHS, Mark Israel e Iain Hay (2006, p. 40) identificaram traços comuns do citado movimento de normatização em diversos países. A principal semelhança relaciona-se ao fato de as iniciativas de regulação terem surgido como resposta a violações éticas ocorridas em pesquisas no campo biomédico, o que desencadeou uma pressão normativa que atingiu as demais áreas, sem respeitar as particularidades dos distintos campos do conhecimento. Outra característica comum apontada pelos mesmos autores, e que nos interessa destacar, está relacionada ao fato de que "[...] as abordagens à regulação ética parecem ter sido dominadas por um caráter de cima para baixo (Estados Unidos, Canadá, Austrália, Noruega) ou de baixo para cima (Reino Unido, Nova Zelândia, África do Sul, Dinamarca)" (ISRAEL; HAY, 2006, p. 40, tradução nossa).

Com relação ao caso brasileiro, o caráter de cima para baixo é evidenciado pelo processo de normatização da conduta em pesquisa nas CHS, que redundou em um modelo caracterizado por pouca margem de autonomia do pesquisador na definição dos cuidados éticos da sua pesquisa. Há uma preponderância da normatização de caráter geral (Resolução CNS No 510/2016), que incide diretamente sobre o pesquisador. Afirma-se isso, pois (1) os CEPs, que poderiam servir como instância de intermediação (entre a norma geral e o pesquisador), atuam preponderantemente em atividades burocráticas de controle, e (2) as opiniões das diferentes entidades representativas das áreas das CHS não foram consideradas no marco regulatório (ver ANPEd, 2019).

Em contraste, no caso português, as instituições nas quais a pesquisa é realizada contam com uma maior autonomia na definição do processo de avaliação dos projetos de pesquisa e, até mesmo, das normas materiais incidentes. Essa característica pode ser entendida a partir do movimento de uniformização de caráter transnacional iniciado pelo processo de Bolonha e que permanece em curso por meio do estabelecimento de orientações da Comunidade Europeia (CE). Dado o caráter transnacional dos princípios materiais e as particularidades locais (dos países membros da CE), um modelo demasiadamente centralizado seria inviável ${ }^{4}$.

\footnotetext{
${ }^{2}$ Resistimos à utilização da expressão regulação da ética na pesquisa por uma questão bastante singela: uma vez apropriada pela normatização, a ética deixa de ser ética e passa a ser normatização. Por isso, utilizamos a expressão regulação da conduta em pesquisa por representar o que de fato está ocorrendo. Guillemin e Gillan (2004) recorrem à utilização dos termos ética processual, como sendo o trâmite burocrático de aprovação de um projeto de pesquisa junto às chamadas comissões de ética, e ética prática, entendida como a verdadeira ética na pesquisa, surgida da atividade do pesquisador com seus dilemas (sobre dilemas éticos na investigação em Psicologia ver Mendes et al., 2016). Apesar de auxiliar na compreensão do papel desempenhado pelas referidas comissões, recusamos esse tipo de apropriação adjetivada da ética, onde ela perde a sua essência e passa a representar o que não é. Esse recurso tem como mais grave consequência a dificultação da partilha do verdadeiro significado da ética (ver Savi Neto e de la Fare, 2019).

${ }^{3}$ Nesse sentido, ver Magalhães (2013) e Amado e Boavida (2008).

${ }^{4}$ Tal qual se tem mostrado inviável o modelo centralizado brasileiro.
}

Práxis Educativa, Ponta Grossa, v. 16, e2115213, p. 1-20, 2021

Disponível em: < https://www.revistas2.uepg.br/index.php/praxiseducativa> 
Por conta disso, o modelo português mescla orientações transnacionais com normativas setoriais e nacionais, como parte do espírito do European Charter for Researchers Ethical Principles (2005, p. 70), o qual estabelece que "[r]esearchers should adhere to the recognised ethical practices and fundamental ethical principles appropriate to their discipline(s) as well as to ethical standards as documented in the different national, sectoral or institutional Codes of Ethics". Mais do que o mero reconhecimento formal de particularidades, o processo de avaliação da conduta dos pesquisadores é, de fato, conduzido com maior grau de intervenção das instituições-sede da pesquisa e da respectiva entidade representativa da área.

Em geral, as Unidades Orgânicas das universidades estabelecem procedimentos e normas próprios a serem observados no âmbito de seus respectivos processos (PEIXOTO et al., 2016). No âmbito da Educação, o instrumento de regulação ético-deontológico (chamado de Carta Ética), que serve de base para as análises dos projetos, foi aprovado por grupo de trabalho constituído pela Sociedade Portuguesa de Ciências da Educação (SPCE), em 12 de setembro de 2014. Na Psicologia, a principal normativa utilizada é o Código Deontológico da Ordem dos Psicólogos Portugueses, aprovado em 2011, com última revisão de 2016, no qual, ao abrigo do Princípio Específico 7, se encontram estabelecidas 14 normas deontológicas em relação à investigação científica. A existência e o protagonismo dessas normativas setoriais representa significativa diferença com relação ao modelo brasileiro, o qual conta com uma única norma de caráter geral (Resolução CNS $\mathrm{N}^{\circ}$ 510/2016), que sequer contou com a participação das entidades representativas das áreas para sua elaboração (ver ANPEd, 2019).

Além das normativas setoriais supramencionadas, existem documentos orientativos em nível da CE que sempre se fazem presentes, como é o caso do Regulamento Geral de Proteção de Dados da União Europeia (RGPD) ${ }^{6}$, de 25 de maio de 2018. O RGPD é uma normativa de cumprimento obrigatório em todos os países-membros, que tem como principal objetivo a proteção da privacidade das pessoas via regulamentação da coleta, do uso e do tratamento de dados pessoais (PEIXOTO, 2017). Além dessas normas, há, ainda, o Código Europeu de Conduta para a Integridade na Investigação, instrumento orientativo sobre aspectos relativos à integridade na pesquisa elaborada no âmbito da Federação Europeia das Academias de Ciências e Humanidades (All European Academies - ALLEA, 2018). E, por fim, há normas das próprias Universidades nas quais a pesquisa é realizada. As normas mencionadas, oriundas de diferentes instâncias, apresentam complementaridade entre si, regulando de maneira mais geral o que é comum às áreas, sem deixar de respeitar as especificidades de cada uma delas.

Feitos esses esclarecimentos, é possível compreender a classificação construída por Israel e Hay (2016) e, por consequência, a regulação da conduta em pesquisa, a partir do grau de intervenção das seguintes quatro esferas de atuação: (1) o próprio pesquisador, (2) a instituição na qual a pesquisa é realizada, (3) a entidade representativa da área principal da pesquisa e (4) as influências externas (controle exercidos por instâncias estranhas às esferas anteriores - como, por exemplo, periódicos no momento da publicação das pesquisas). Com especial atenção (1) ao grau de autonomia conferido e executado por essas quatro esferas no processo de regulação da conduta em pesquisa e à centralização do controle normativo e (2) tomando como principal referencial teórico o modelo construído por Israel e Hay (2016), será realizada a análise dos dados coletados e da respectiva normatização.

\footnotetext{
5 "Os pesquisadores deveriam aderir às práticas éticas reconhecidas e aos princípios éticos fundamentais apropriados à(s) sua(s) disciplina(s), bem como aos padrões éticos documentados nos diferentes Códigos de Ética nacionais, setoriais ou institucionais" (EUROPEAN CHARTER...2005, p. 70, tradução nossa).

${ }^{6}$ Para uma comparação entre o RGPD e as normas brasileiras, ver Mangeth (2018).
}

Práxis Educativa, Ponta Grossa, v. 16, e2115213, p. 1-20, 2021

Disponível em: <https://www.revistas2.uepg.br/index.php/praxiseducativa> 


\section{Considerações metodológicas}

O presente estudo tem caráter exploratório e abordagem quanti-qualitativa, valendo-se da análise documental e do levantamento de opiniões colhidas por meio da técnica do survey. O projeto de pesquisa no qual se insere este artigo está registrado na Comissão Científica da Pontifícia Universidade Católica (PUCRS), cumprindo todos os protocolos relativos à ética.

O questionário online teve sua primeira versão elaborada em 2016 para o caso brasileiro, no campo da Educação, quando foi testado e aprovado no âmbito do Grupo de Pesquisa Formação, ética e pesquisa em Educação, com a participação de professores especialistas na área, convidados para essa atividade. Em estudos posteriores, com resultados já publicados (DE LA FARE; CARVALHO; PEREIRA, 2017; DE LA FARE; SAVI NETO, 2019; SAVI NETO; DE LA FARE, SILVA, 2020), o formulário sofreu pequenas alterações com a finalidade de adequá-lo aos diferentes públicos-alvos.

A versão do questionário utilizada em Portugal foi formulada observando-se as particularidades nacionais. $O$ formulário conta com 15 questões fechadas, 10 abertas e uma questão com a escala de Likert. Ele foi dividido em três blocos: as dez primeiras perguntas buscam a caracterização geral dos respondentes; as perguntas de 11 a 15 têm o objetivo de conhecer a formação dos respondentes no tema da ética; e, por fim, as perguntas de 16 a 24 possuem a finalidade de obter dados sobre a relação dos respondentes com a ética a partir da sua prática em pesquisa.

A coleta dos dados teve início em março de 2019, com consultas ao site da Direção-Geral do Ensino Superior de Portugal (DGES). Foram realizadas buscas, na modalidade avançada, com o preenchimento dos campos "curso" (Psicologia ou Educação), "tipo de ensino" (considerado sempre como "universitário"), "tipo de estabelecimento" (público ou privado), "área" (de acordo com o curso) e "tipo de curso" (sempre doutoramento) ${ }^{7}$. Respectivamente aos campos retroindicados, foram utilizados os seguintes descritores, que recuperaram os resultados a seguir: 13 cursos em Educação oferecidos por 12 instituições e unidades orgânicas públicas de ensino; dois cursos em Educação oferecidos por duas instituições e unidades orgânicas privadas; 10 cursos de Psicologia, oferecidos por sete instituições e unidades orgânicas públicas de ensino; e, por fim, quatro cursos em Educação ofertados por quatro instituições e unidades orgânicas privadas. Esses dados permitiram reconhecer um total de 15 cursos de doutoramento em Educação e $14 \mathrm{em}$ Psicologia. O total de 29 cursos identificados é oferecido por treze instituições públicas e sete da iniciativa privada.

Com base nesse mapeamento, foram enviados e-mails para os diretores dos cursos localizados no site da DGES, contendo: (1) a apresentação da pesquisa, (2) o link para o questionário e (3) a solicitação do encaminhamento do inquérito aos estudantes de doutoramento matriculados nos cursos sob sua direção. Essa comunicação foi organizada a partir de três rodadas de envio de e-mails aos diretores. Na primeira, realizada entre os dias 20 e 30 de maio de 2019, oito diretores responderam positivamente ao encaminhamento do inquérito para os estudantes de seus cursos; na segunda, realizada no dia 12 de setembro de 2019, enviada apenas para os não-respondentes da tentativa anterior, outros oito responderam positivamente ao encaminhamento do questionário; e, na terceira e última, não houve novas respostas positivas. De modo que, no total, houve resposta

\footnotetext{
${ }^{7}$ Considerando-se que a aprovação para que os Institutos Politécnicos ofereçam cursos de doutoramento é recente, de junho de 2018, constam apenas doutoramentos oferecidos no âmbito do ensino universitário no site da DGES à data de nossa consulta (nesse sentido, ver Silva, 2018).
} 
positiva de 16 dos 29 cursos de doutoramento contatados. Com base nesse procedimento, foi possível obter 36 respostas, sendo 18 de cada curso (Psicologia e Educação).

A análise das respostas foi feita com base na Hermenêutica Objetiva (VILELA, 2009, 2011; VILELA; NOACK-NAPOLES, 2010), método desenvolvido por Ulrich Oevermann (SAVI NETO, 2018), objetivando incrementar o acesso ao objeto da pesquisa, para além da mera aparência do discurso por meio "[...] de análises concretas, que se ajustando ao objeto estudado, levam o objeto a se expressar" (OEVERMANN, 1983 apud VILELA, 2009, p. 84). A escolha de tal método de interpretação deve-se ao objetivo do projeto de pesquisa como um todo de contrastar a relação entre a situação concreta da ética em pesquisa em um modelo fundado na normatização com outro modelo que seria possível a partir de uma consistente formação moral dos pesquisadores.

Por fim, com relação à construção do referencial teórico, buscaram-se prioritariamente publicações recentes sobre o tema nas duas áreas escolhidas das CHS em Portugal. Entretanto, o tema vem ganhando algum destaque somente a partir de 2014, com poucas obras autorais e com a produção existente concentrada majoritariamente em artigos (CARVALHO, 2018, p. 157-158). Por conta disso, para complementar o referencial teórico, recorreu-se (1) à produção de outras das CHS, com destaque à Antropologia, uma das áreas mais militantes na temática (CARVALHO, 2018) e (2) a estudos de caráter internacional pertinentes à temática e à abordagem pretendida.

\section{Resultados e discussão}

a) Perfil dos respondentes

Considerando-se que o objetivo do presente artigo está relacionado à regulamentação da conduta em pesquisa nas CHS, os dados de caracterização geral dos respondentes serão apresentados de forma simplificada (com o número de ordenação das perguntas indicado entre colchetes). Sobre a idade: [1] 33,3\% disseram ter entre 31 e 40 anos; 30,5\%, entre 41 e 50 anos; $22,2 \%$, entre 20 e 30 anos; e 13,8\%, mais de 50 anos. Na pergunta [2]: 44,4\% indicaram a Psicologia como área de formação; 27,7\% Educação; e 27,7\%, outros cursos (licenciaturas específicas). Na questão [3]: 41,6\% disseram ter cursado o Mestrado em Psicologia; 27,7\%, em Educação; 8,3\%, em Ciências da Educação; e 22,2\%, em outra área. Com relação ao ano de início no Doutorado [4]: $25 \%$ iniciaram em 2019; 16,6\%, em 2018; e 58,4\%, antes de 2018. Com relação à conclusão do curso [5]: 44,4\% têm a conclusão do Doutorado prevista para depois de 2021; 33,3\%, em 2019; $8,3 \%$, em 2020; e 14\%, em outros anos.

As perguntas [6], [7] e [8] buscaram informações sobre o relacionamento dos respondentes com o Doutorado. Na pergunta [6], 33,3\% disseram dedicar de $25 \%$ a $50 \%$ do seu tempo para as atividades do curso; 33,3\% afirmaram que dedicam de $91 \%$ a $100 \% ; 13,8 \%$ referiram de $51 \%$ a $70 \% ; 11,1 \%$, de $71 \%$ a $90 \%$; e $8,3 \%$, menos de $25 \%$. Na pergunta [7]: $47,2 \%$ afirmaram que, além de não receber remuneração no Doutorado, ainda precisam pagar taxas acadêmicas; 36,1\% recebem bolsa; 11,1\% recebem outra forma de remuneração relacionada ao Doutorado; e 5,5\% afirmaram que não recebem remuneração, mas que não precisam pagar as taxas acadêmicas. No tocante à área na qual realizam as atividades de pesquisa [8]: 11,1\% pesquisam sobre Formação de Professores; 8,3\%, em Fundamentos da Educação; 8,3\%, sobre Política Educacional; e os outros $72,1 \%$ referiram as mais diversas áreas da Psicologia e da Educação.

Para encerrar essa breve caracterização geral, os dados sobre a eventual atuação profissional dos respondentes apontaram que: [9] 58,3\% colaboram em atividades de ensino; e 41,7\%, não. Sobre a realização de outras atividades profissionais além da investigação [10], 50\% atuam como

Práxis Educativa, Ponta Grossa, v. 16, e2115213, p. 1-20, 2021 Disponível em: < https://www.revistas2.uepg.br/index.php/praxiseducativa> 
professores; 8,3\% dedicam-se a diversas atividades no âmbito da psicologia (como Psicoterapia, Assessoria, Clínica e Avaliação Neuropsicológica) e os demais dedicam-se exclusivamente à investigação.

\section{b) Formação em Ética}

$\mathrm{Na}$ segunda parte do questionário, perguntas de [11] a [15], buscaram-se informações sobre a formação em ética dos respondentes. Importante esclarecer que, em Portugal, a integração de uma disciplina de ética no plano de estudos da formação inicial em Psicologia é recente e surgiu, essencialmente, como decorrência da reestruturação do curriculum para efeitos da sua adequação ao processo de Bolonha - conforme Decreto-Lei No 74/2006, de 24 de março (PORTUGAL, 2006) -, tendo como referencial o Diploma Europeu de Psicologia (LUNT, 2005) e as suas orientações em relação aos requisitos da qualificação dos psicólogos na Europa.

Da mesma forma, a inclusão de uma disciplina de Ética é recente nos planos dos cursos da formação em Educação, tendo como principal referência normativa o Decreto-Lei $N^{\circ} 79 / 2014$, de 14 de maio (PORTUGAL, 2014a), corrigido pela Declaração de Retificação No 32/2014, de 27 de junho (PORTUGAL, 2014b), que inclui a componente de formação Área cultural, social e ética, para o nível de Mestrado, ausente, desse modo, da Graduação, também como parte da adequação ao processo de Bolonha.

Nesse sentido, [11] perguntou-se sobre a oferta de formação específica sobre ética durante o percurso acadêmico dos respondentes (com a possibilidade de escolher mais de uma resposta): $61,1 \%$ afirmaram que não houve uma disciplina específica, mas que os aspectos éticos foram abordados transversalmente em outras disciplinas; 19,4\% disseram ter cursado uma disciplina específica na Graduação; 11,1\%, uma disciplina específica no Mestrado; 8,3\%, uma disciplina específica no Doutorado; e os restantes, que representam 19,4\%, referiram oportunidades pontuais (como palestras e seminários isolados).

Embora seja expressivo o percentual de respondentes que teve um ensino transversal da ética durante sua trajetória acadêmica, é preocupante perceber que quase $40 \%$ não tiveram a oportunidade de cursar uma disciplina específica sobre o tema, orientada por um professor especialista na matéria. A ética é componente central da formação, e o fato de não ser objeto de uma disciplina própria ministrada por um especialista demonstra a pouca importância conferida ao seu estudo.

Para além da percepção sobre o tratamento explícito do tema da ética, os respondentes foram interrogados, por meio de pergunta aberta [12], se a formação cursada na Graduação e no Mestrado teve em conta aspectos éticos. As respostas foram: 52,7\% afirmaram que teve pouco em conta; $30,5 \%$, que teve em conta, e 16,6\%, que a ética esteve muito presente ao longo da formação. [13] A mesma pergunta foi feita com relação ao Doutorado e, nesse caso, 44,4\% disseram que tal nível de formação teve em conta aspectos éticos; $33,3 \%$, que teve pouco em conta; e $26,6 \%$, que teve muito em conta.

Merece nota que, embora as questões [12] e [13] se referissem à ética lato sensu, um número expressivo dos respondentes restringiu a sua resposta a aspectos ligados à regulação da conduta (como se ética em pesquisa estivesse limitada ao aspecto normativo). Os percentuais dos que restringiram a ética à normatização foram de $50 \%$ com relação ao Mestrado e à Licenciatura e 69,4\%, ao Doutorado. Nas respostas à pergunta [12]: 22,2\% usaram a palavra "transversal" para referir-se à presença da Ética na Graduação e no Mestrado; e outros 22,2\%, mesmo sem a utilização da palavra, incluíram a ideia de transversal (totalizando 44,4\%); outros 33,3\% definiram a consideração de aspectos éticos com termos como "pouca", "muito pouca", "nenhuma", 
“insuficiente", totalizando $77,7 \%$ que demonstraram insatisfação com a formação em ética nessas duas importantes etapas da formação. Dos $22,3 \%$ restantes, $5,5 \%$, mesmo considerando suficiente a formação em Ética, referiram dificuldades na compreensão dos aspectos éticos, julgados pelos respondentes como "abstratos". Esses dados corroboram a análise às respostas da pergunta [11] sobre as repercussões negativas da ausência de uma disciplina específica sobre ética.

Ao analisarem-se as respostas à pergunta [13] (consideração de aspectos éticos na formação de Doutorado), nota-se um direcionamento ainda maior para as questões normativas. Destaca-se que o uso do termo "transversal" caiu para $2,7 \%$ e o uso da ideia de transversal manteve-se em $22 \%$. Contudo, em se tratando de doutorandos, alguns ainda não possuíam a apreciação completa da formação ${ }^{8}$. Outros dados interessantes: por um lado, 13,8\% percebem no Doutorado uma maior consideração dos aspectos éticos do que no Mestrado; por outro lado, sentem falta de formação prévia para acompanhar o nível das discussões, enquanto 8,3\% sentem necessidade de buscar formação complementar para suprirem lacunas do Doutorado com relação aos aspectos éticos do projeto de tese.

Considerando-se que, do ponto de vista normativo, a inclusão de disciplinas sobre ética é recente nos cursos sob análise e que, do ponto de vista dos dados coletados, um percentual expressivo afirmou não ter cursado uma disciplina específica sobre o tema, os grupos de pesquisa e as reuniões de orientação têm amplificada a sua importância como espaços formativos em ética. A relevância de tais espaços pode ser entendida na medida em que eles aproximam pesquisadores seniores com pesquisadores em formação, permitindo aos segundos espelharem-se na conduta dos primeiros.

Com base nesse entendimento, perguntou-se [14] aos pesquisadores respondentes sobre a formação e/ou discussão sobre ética nos grupos de pesquisa dos quais tomam parte: 41,6\% disseram que as questões éticas são debatidas de forma suficiente nos grupos; $16,6 \%$ disseram que tal tema é tratado apenas nas reuniões de orientação; 8,3\% disseram que o grupo de pesquisa do qual fazem parte não realiza reuniões; $8,3 \%$ disseram que não participam das reuniões; e outros $33,3 \%$ responderam outras alternativas, sem especificá-las.

Para fechar o bloco sobre a formação em Ética, perguntou-se [15] qual a principal forma de obtenção de conhecimentos ou aprofundamento sobre o tema da ética: 41,6\% afirmaram buscar informações por meio do diálogo com o orientador e outros colegas; $33,3 \%$ disseram ler livros e artigos sobre o tema; $8,3 \%$ mencionaram a mídia como fonte; $8,3 \%$ admitiram não buscar informações sobre o tema; $5,5 \%$ disseram que procuram formações específicas; e 2,7\% não responderam.

Dentre os dados coletados nas respostas às perguntas [14] e [15], destaca-se o elevado percentual de respondentes portugueses que referiu o aprofundamento do tema mediante diálogo com o(a) professor(a) orientador(a) (41,6\%), confirmando a importância dessa instância alternativa de formação em ética. Se, por um lado, os grupos de pesquisa e as conversas com os orientadores podem ser oportunidades importantes de aprendizagem sobre o tema da ética em pesquisa; por outro lado, sendo recente a integração nos planos de estudos de disciplinas sobre ética, é razoável supor que os próprios pesquisadores não tenham passado por uma formação sobre ética em pesquisa devidamente atualizada e orientada.

Nesse sentido, sem colocar em causa a importância da experiência acumulada, não é cabalmente possível garantir a qualidade da formação ética dos que desempenham o papel de

\footnotetext{
${ }^{8}$ Considerando-se as respostas à pergunta sobre o ano de conclusão do Doutorado, pode-se estimar que $44,4 \%$ dos respondentes estavam cursando o primeiro ou o segundo ano do curso.
} 
orientadores/supervisores dos trabalhos de pesquisa das novas gerações de investigadores, sendo este um aspecto que nos faz refletir sobre a pertinência de iniciativas que permitam o desenvolvimento de competência de raciocínio e decisão ética orientadas também para os que assumem especial responsabilidade na iniciação científica dos mais jovens. Além disso, realizandose uma hermenêutica objetiva desses dados, é possível afirmar que uma formação pouco consistente em ética pode ser relacionada a pesquisadores que confiam de forma exagerada na normatização como forma de assegurar a ética na pesquisa.

c) Ética na prática de pesquisa

No terceiro e último bloco do questionário (perguntas de [16] a [24]), buscaram-se dados sobre a relação dos respondentes com a ética a partir da prática em pesquisa. Esse terceiro bloco teve como finalidade central tensionar a relação entre a autonomia dos pesquisadores, entendida no âmbito do presente estudo como a capacidade de compreender e aplicar por si só os aspectos éticos e normativos envolvidos na atividade de pesquisa, com o caráter instrumental da normatização, como mero instrumento de controle sobre a pesquisa, tendo em conta o papel desempenhado pelas universidades nessa relação. Para auxiliar na compreensão da análise das respostas, serão realizadas inversões na ordem de apresentação das perguntas, com agrupamento dos dados de acordo com a pertinência temática da análise.

É importante referir que, de acordo com as informações disponibilizadas nos endereços eletrônicos das 20 instituições utilizadas para fins de composição da amostra portuguesa, 12 possuem uma única Comissão de Ética para todos os cursos (embora multidisciplinares), quatro contam com Comissões por área de conhecimento, duas possuem Comissão apenas para a área da saúde, e outras duas possuem apenas Códigos de Conduta, mas ainda não constituíram comissões próprias. Nesse sentido,

[...] em Portugal, a existência deste tipo de comissões [de ética] é marginal. Nos subsistemas politécnico público e universitário privado somente duas instituições divulgam publicamente a sua existência, explicitando as principais funções e as atividades dos respetivos conselhos ou comissões de ética. Nomeadamente, a Escola Superior de Tecnologias da Saúde do Instituto Politécnico de Lisboa e a Universidade Fernando Pessoa. Já para o subsistema universitário público pudemos referenciar e analisar os documentos enquadradores das comissões de ética e deontologia da Universidade de Aveiro; da Universidade do Minho; da Universidade do Porto; da Universidade de Trásos-Montes e Alto Douro; e do ISCTE- IUL. (PEIXOTO et al., 2016, p. 216).

Nessa linha, a exigência de análise dos projetos de dissertação e de tese por comissões de ética é recente e ainda não-obrigatória em todas as universidades. O fato de que a tramitação dos projetos de pesquisa por instâncias de controle normativo é recente no modelo português ficou evidenciado nas respostas à pergunta [17], com relação à submissão de projeto de pesquisa à análise de alguma Comissão de Ética, para a qual tivemos o expressivo percentual de 41,6\% que afirmaram nunca ter submetido algum projeto a referidas comissões. Complementando o percentual: 30,5\% disseram já ter submetido projetos mais de uma vez; e 27,7\%, uma única vez.

Por um lado, esses dados demonstram a autonomia das instituições de Ensino Superior na definição de seus processos internos, mas, por outro lado, do ponto de vista prático, os estudantes que não submetem seus projetos de pesquisa à análise de uma Comissão de Ética dificilmente têm sucesso em publicá-los: "[a] necessidade, por exemplo, de passar por uma comissão de ética para poder publicar em revistas indexadas é uma nova regra do jogo [...]” (JORGE, 2014b, p. 38).

A pergunta [17] foi desdobrada em outros dois itens que foram respondidos apenas pelos $58,2 \%$ dos pesquisadores que afirmaram já ter submetido algum projeto à análise de alguma Comissão de Ética. A primeira parte [17.1] questionou os investigadores sobre a principal razão 
pela qual submeteram o(s) seu(s) projeto(s) à avaliação de uma Comissão de Ética: 42,8\% afirmaram que foi por orientação do orientador ou da instituição-sede da pesquisa; $38,1 \%$, por convicção de que se tratava do certo; e 19\%, por solicitação de entidades externas. Esses dados sugerem que a tramitação dos projetos de pesquisa em comissões de ética parece estar mais associada a uma etapa burocrática a ser seguida do que como uma garantia de correção ética do procedimento, afinal $61,9 \%$ dos respondentes apontaram causas alheias à própria convicção para adoção do referido procedimento.

A exemplo de Fernandes (2020), deve-se interrogar sobre qual a função que a normatização dos procedimentos de investigação tende, verdadeiramente, a cumprir e que, expressivamente, o autor qualifica como ortopédica:

\begin{abstract}
Num contexto destes, a insistência discursiva e procedimental em torno da ética corresponde de facto a uma preocupação com a sua substância? Ou andamos a chamar ética à produção de novas vigilâncias e à emanação de regulamentações? E, nesse caso, não estaremos a reduzir a ética ao plano meramente instrumental das normatividades, numa espécie de ortopedia moral que acomete o sistema científico? (FERNANDES, 2020, p. 45).
\end{abstract}

Para viabilizar um modelo de vigilância, tal qual mencionado pelo autor, é necessário que haja considerável grau de desconhecimento por parte dos pesquisadores sobre (1) a normatização e o funcionamento do modelo de regulação e (2) os conceitos éticos fundamentais à pesquisa, o que seria compatível com as lacunas formativas percebidas no segundo bloco do questionário. "Como se concordará facilmente, os códigos de conduta estão na moda e vivem hoje uma conjuntura favorável" (FRADA, 2014, p. 143), entendida como um cenário marcado pelo pouco conhecimento sobre as normas e sobre o conteúdo tutelado. Buscando dados para mensurar o grau de desconhecimento sobre o sistema de regulação, analisaremos em conjunto as respostas às perguntas [17.2], [18] e [20].

$\mathrm{Na}$ segunda parte da pergunta [17], com relação à percepção dos pesquisadores sobre o trâmite do projeto na Comissão de Ética [17.2]: 38,1\% asseveraram que o processo é rápido e a preparação dos documentos é simples; $33,3 \%$, que o processo é demorado e burocrático, mas a preparação dos documentos é simples; $24 \%$, que o processo é demorado e burocrático e a preparação dos documentos é complicada; $4,7 \%$, que o processo é rápido, mas a preparação dos documentos é complicada.

A pergunta [18] solicitava, de forma aberta, a opinião dos respondentes com relação ao grau de preparação das comissões de ética para compreenderem as especificidades dos projetos de pesquisa sob sua análise. Categorizando as respostas, é possível afirmar que 52,7\% confiam na competência das referidas comissões, $27,7 \%$ disseram não conhecer suficientemente a questão para opinarem e 19,4\% julgam que não estão preparadas.

E, finalizando esse grupo de perguntas, com relação ao conhecimento que os pesquisadores julgam possuir sobre os regulamentos aplicáveis aos seus projetos (pergunta aberta [20]): 55,5\% disseram não conhecer suficientemente; 38,8\% julgam conhecer de forma suficiente e 5,5\% não responderam.

Os dados coletados nas perguntas [17.2], [18] e [20] indicam que: 28,6\% percebem como complicada a preparação dos documentos a serem apresentados às comissões de ética; $27,7 \%$ disseram não conhecer suficientemente sobre a Comissão de Ética para afirmarem que ela está preparada para proceder análises adequadas às especificidades dos projetos apreciados; e 55,5\% admitiram não conhecer suficientemente a normatização. Embora tais percentuais sejam compostos de respondentes que se repetem, demonstram, ainda assim, um significativo grau de 
desconhecimento sobre o sistema de regulação (o que pode ser explicado, mas não justificado, pelo fato de que se trata de um modelo recente).

Complementando a análise, agora com atenção à clareza conceitual em questões éticas demonstrada pelos respondentes, analisar-se-á conjuntamente as perguntas [16] e [19]. Perguntouse [16], de forma aberta, sobre o enfrentamento de algum dilema ético na atividade de pesquisa. Categorizando as respostas, tem-se que 33,3\% disseram nunca ter enfrentado um dilema ético; $30,5 \%$, sim; e 36,1\% optaram por não responder. Sem afirmar peremptoriamente a falta de compreensão dos respondentes com relação ao significado do conceito de dilema, nem da sua capacidade para reconhecerem um dilema ético, é de surpreender que apenas 30,5\% tenham declarado já terem se deparado com esse tipo de situação inerente à prática da pesquisa nas CHS. Tal percentual fica ainda mais expressivo ao olhar-se com desconfiança para os 36,1\% que deixaram de responder a essa pergunta.

Seguindo na mesma linha, outro conceito material fundamental para a pesquisa está relacionado aos riscos envolvidos na pesquisa. Assim, perguntou-se [19] sobre os riscos acarretados aos participantes de pesquisas nos seus respectivos campos (Psicologia e Educação). Os pesquisadores ofereceram diversas respostas, merecendo destaque que $25 \%$ disseram que não há riscos e 5,5\% desconhecem a possibilidade de riscos. Tal percentual é expressivo na medida em que ambos os campos de pesquisa, Educação e Psicologia, envolvem potenciais riscos aos participantes.

Nesse sentido, um modelo de regulação marcado pelas duas ordens de desconhecimento evidenciadas nas respostas às perguntas [16], [17], [18], [19] e [20] tende a gerar uma confiança cega (1) nas esferas hierárquicas superiores e (2) na regulação, simplesmente pelo seu caráter normativo, independentemente de seu conteúdo material. Uma resposta à pergunta [20] chama especial atenção sobre o referido excesso de confiança hierárquica: "Não tenho muito conhecimento sobre isso, foi sempre feito por superiores, responsáveis pelos projetos que integro" (Doutorando em Psicologia 34, 2019).

No tocante ao grau de confiança na normatização, tem-se a pergunta [21]: "Na sua opinião, a ética na investigação pode ser promovida principalmente através de (i) formação, de (ii) regulação externa ou de (iii) ambas? Justifique a sua resposta, por favor". Agrupando por campo do conhecimento os percentuais da pergunta [21], tem-se que: dos 18 respondentes que realizam pesquisas principalmente na Psicologia, $72,2 \%$ afirmaram que a ética em pesquisa está vinculada a ambas; $11,1 \%$, formação; 11,1\%, regulação; e 5,5\%, sem opinião. Dentre os 18 respondentes do campo Educacional: 72,2\%, ambas; 16,6\%, formação; 5,5\%, regulação; e 5,5\%, sem opinião. Esses percentuais são significativos na medida em que apenas 11,1\% dos doutorandos em Psicologia e $5,5 \%$ em Educação acreditam na formação como principal forma de promoção da ética em pesquisa.

Ainda que se argumente sobre um eventual caráter complementar entre formação e regulação, a pergunta utilizou o termo "principalmente" para indicar que as duas formas não estavam sendo tratadas de maneira excludente com relação à promoção da ética em pesquisa. Isso demonstra um elevado grau de associação dos respondentes entre ética e normatização. Para uma desejável mudança nessa mentalidade, as próprias comissões de ética, órgãos associados ao sistema de controle, poderiam funcionar como agentes de desburocratização do modelo: "[...] uma comissão de ética universitária que valoriza a autonomia, esse caminho seria mais desejável do que uma regulação heterónoma que evidenciaria que, afinal, já somos capazes de tomar conta de nós" (JORGE, 2014b, p. 38). 
As respostas à pergunta [21] confirmam uma ideia muito presente no conhecimento popular de que a construção de uma sociedade pautada em valores éticos depende principalmente da ampliação e do endurecimento do controle normativo. Esse comportamento com relação às normas favorece o que uma parte da Antropologia vem chamando de audit society. Nesse sentido:

\begin{abstract}
Alguns antropólogos têm desenvolvido a noção de audit society (Shore e Wright 1999; Strathern 2000) para falar de uma cultura latente no ensino superior dos últimos anos, onde um regime cada vez mais rigoroso de auditoria e inspeção - sob o propósito da manutenção da qualidade, seletividade da investigação, revisões das aulas, etc. - foi instituído. Alguns autores identificam que a ética, as revisões éticas e as comissões de ética que se têm formado nas instituições de investigação e de ensino, na forma de IRB, REC, etc., são precisamente uma extensão desta nova cultura ligada à noção de audit society (Pels 1999; Strathern 2000). (RORIZ; PADEZ, 2017, p. 79).
\end{abstract}

Shore e Wright (1999) argumentam que a invasão das universidades pela audit culture é parte do movimento de forçosa e artificialmente mensurar e controlar a educação com mecanismos e critérios advindos do mercado financeiro, utilizando recursos como Research Assessment Exercises e Teaching Quality Assessment. Na mesma linha de interpretação de referidos autores, que trabalharam essa perspectiva aplicada ao ensino universitário britânico, Marilena Chaú, no mesmo ano, publicou o texto $A$ Universidade Operacional, no qual afirma a desarticulação da educação como direito e serviço público e sua rearticulação com bases meramente econômicas, lançando mão de recursos como avaliações de eficácia e eficiência, que seriam mensuráveis a partir de critérios de gestão e de desempenho (CHAUÍ, 1999).

Ambas as abordagens supramencionadas questionam o argumento de que tais mecanismos de accountability (palavra que encerra uma ideia de prestação de contas) seriam instrumentos capazes de conferir transparência, neutralidade e objetividade na avaliação das Universidades, pois entendem que tal maneira de estruturar a educação se trata de uma pulverização e proliferação de instâncias com objetivo de controle sobre a atividade de pesquisa. Utilizando-se da obra O processo, de Kafka, como metáfora, Shore e Wright (1999) afirmam a necessidade de reflexividade politica por parte de professores e pesquisadores sob pena de atuarem como meros agentes de exercício de poder, tal qual faziam os guardas da mencionada obra do escritor nascido em Praga, que estavam a serviço de uma autoridade que sequer conheciam, mas na qual confiavam cegamente (KAFKA, 1976).

A atualidade e a pertinência desses textos referidos devem-se ao fato de que, conforme previsto pelos próprios autores que criaram o conceito, a audit culture é progressiva, instalando-se em cada vez mais instâncias. Essa é a leitura de Peter Pels (1999) que inclui o movimento de normatização da conduta em pesquisa e a proliferação de códigos e comissões de ética como parte da expansão da audit culture. Importante destacar que essa análise é realizada no âmbito da Antropologia, área das CHS que vem tentando resistir de maneira mais forte ao controle externo à atividade de pesquisa (ainda mais especificamente, na área da pesquisa etnográfica). Corroborando o afirmado, a Sociedade Portuguesa de Antropologia ainda não adotou um código de conduta próprio e, no Brasil, a Associação Brasileira de Antropologia, que conta com um código de ética próprio desde a década de 1980, igualmente representa um forte espaço de resistência ao controle externo à atividade de pesquisa.

Mesmo tratando-se de uma análise do âmbito da Antropologia, o conceito de audit society mostra-se aplicável ao movimento de normatização das CHS como um todo. O que parece motivar uma reação mais forte de referido campo do conhecimento é o grau de interferência que as normas de caráter geral, normalmente inspiradas na área biomédica, causam na atividade de pesquisa. A relação estabelecida por Shore e Wright (1999) entre uma burocracia cega kafkiana e as instâncias

Práxis Educativa, Ponta Grossa, v. 16, e2115213, p. 1-20, 2021

Disponível em: < https://www.revistas2.uepg.br/index.php/praxiseducativa> 
de controle da atividade da pesquisa é motivo de reflexão também em Portugal, para além do campo da Antropologia:

Mais curioso, ainda, é reparar que, no seu quotidiano e dispersos em múltiplas obrigações profissionais, os próprios membros das comissões de ética, quando diante de um projeto de investigação e face à necessidade de dar um parecer sobre a sua qualidade ética, procedem, envolvidos num tipo de burocracia, confrontando-o com os itens que estão consensualmente ou legalmente aceites, medindo o seu encaixe ou desvio de um padrão e contribuindo, indiretamente, para essa percepção geral de que a ética se resume a um conjunto de itens a respeitar, sob pena de não se ver o trabalho financiado ou publicado (JORGE, 2014a, p. 26).

Nessa linha, a referida sobrevalorização do aspecto normativo voltou a aparecer nas respostas à pergunta [23], sobre a presença da ética na prática pessoal de pesquisa: 64\% responderam combinando aspectos normativos e éticos; 30,5\% responderam dando maior ênfase ao aspecto normativo; e 5,5\% optaram por não responder. De todas as respostas, algumas são particularmente ilustrativas quanto à ênfase no aspecto normativo:

\begin{abstract}
Procuro garantir que o meu trabalho respeita os princípios éticos e deontológicos dos psicólogos, nomeadamente o respeito pelo Princípio Específico 7 - Investigação, do Código Deontológico da Ordem dos Psicólogos Portugueses, publicado na $2^{\mathrm{a}}$ Série do Diário da República a 20 de Abril de 2011, Regulamento No 258/2011. Destaco, essencialmente, o consentimento informado, a participação voluntária, os direitos fundamentais dos participantes, o anonimato e a confidencialidade dos dados recolhidos e o respeito pelos direitos de autor (Doutorando em Psicologia 18, 2019).
\end{abstract}

Procuro realizar o meu trabalho de forma mais imparcial possível (Doutorando em Educação 20, 2019).

Procuro cumprir com os normativos legais em vigor, tendo o cuidado de consultar os mais recentes (Doutorando em Educação 22, 2019).

Procuro manter sempre presente o Código de Ética e Deontologia na investigação para que não prejudique terceiros e a mim (Doutorando em Psicologia 27, 2019).

Com base em uma análise sistemática das respostas oferecidas ao questionário, é possível afirmar que, na maioria, os respondentes evidenciaram uma forte associação da ética com as normas. Tal relação é comum e encontrada de forma recorrente no conhecimento popular, esfera na qual a ética é entendida como uma espécie de freio, de limitação à liberdade dos sujeitos. Essa noção é exemplarmente representada pela seguinte resposta à pergunta [21]: "A ética é uma questão, fundamentalmente, pessoal e cultural. Infelizmente, o povo português não tem este valor muito presente na sua vida. Desta forma, o controlo tem que ser mais apertado" (Doutorando em Psicologia 14, 2019) $)^{9}$.

De forma tão frontal quanto eloquente, Fernandes (2020) alerta para os perigos da sobreconfiança nas normas como mecanismos de controle externo que se justificam mais pela expectativa de fraude do que por imperativos éticos:

É preciso interrogar esta vontade de criar a todo o preço normas a uma prática que se quer autónoma, responsável, competente e íntegra. O importante é trabalhar valores e não empossar fiscais - doutro modo estamos a favorecer uma regressão à menoridade do indivíduo. É preciso reaproximarmo-nos da ética da confiança e resistirmos à tentação da normatização, que nos impele para éticas mais estritas, a que já vimos chamar éticas da suspeição. (FERNANDES, 2020, p. 46).

\footnotetext{
${ }^{9}$ Essa preocupante descrença no potencial reflexivo dos sujeitos também foi observada nas respostas ao questionário aplicado a doutorandos brasileiros.
} 
Entretanto, há também de valorizarem-se as respostas que manifestaram resistência a esse impulso normativo, demonstrando a compreensão dos pesquisadores no sentido de que a ética em pesquisa possui um caráter autônomo com relação à normatização. Têm-se as seguintes respostas à pergunta [20] como representativas dessa compreensão:

Como trabalho especialmente na Psicologia Crítica, os processos éticos atravessam todo o processo de investigação que desenvolvo. Além disso, tenho presente a ética não apenas como uma dimensão na investigação, mas também como projeto de vida! $O$ questionamento constante é questionar os limites das nossas práticas, nomeadamente na investigação acredito que seja fundamental não apenas para o desenvolvimento da ciência, mas também para a transformação social. Se a investigação não é comprometida com a vida das pessoas e com a ética, ela para mim de "pouco" serve (Doutorando em Psicologia 1, 2019).

É o ar que se respira (Doutorando em Educação 7, 2019).

A ética está presente na minha vida. A investigação faz parte da minha vida. Uma não poderia existir sem a outra (Doutorando em Psicologia 14, 2019).

Para mim, pessoalmente, a questão da ética é fundamental. Penso que, na investigação, para que esta faça sentido e para seja promotora e do conhecimento e até da mudança, é fundamental que toda a atuação seja pautada pela ética (Doutorando em Educação 30, 2019).

Esse reconhecimento da ética como aspecto fundamental do processo de pesquisa ficou evidenciado nas respostas à pergunta [22], que teve como objetivo conhecer a percepção dos pesquisadores sobre a importância que consideram assumida pelos aspectos éticos em cada uma das fases do processo de pesquisa, utilizando a escala de Likert e tendo a pontuação "1" para "minimamente importantes" e "10" para "maximamente importantes" (Tabela 1).

Tabela 1 - Importância dos aspectos éticos nas etapas da pesquisa

\begin{tabular}{l|c|c|c|c|c|c|c|c|c|c|c}
\hline & \multicolumn{5}{|c}{ Frequência da pontuação atribuída } \\
\hline Tarefas de investigação apresentadas & $\mathbf{1}$ & $\mathbf{2}$ & $\mathbf{3}$ & $\mathbf{4}$ & $\mathbf{5}$ & $\mathbf{6}$ & $\mathbf{7}$ & $\mathbf{8}$ & $\mathbf{9}$ & $\mathbf{1 0}$ & T.P.10 \\
\hline 1. Escolha do tema de pesquisa & 4 & 0 & 3 & 4 & 2 & 2 & 4 & 11 & 3 & 3 & 224 \\
\hline 2. Definição dos objetivos & 3 & 0 & 2 & 4 & 0 & 3 & 2 & 12 & 5 & 5 & 248 \\
\hline 3. Revisão da literatura & 6 & 1 & 3 & 6 & 4 & 2 & 5 & 6 & 0 & 3 & 186 \\
\hline 4. Estruturação do plano metodológico & 1 & 1 & 1 & 3 & 2 & 1 & 3 & 12 & 4 & 8 & 270 \\
\hline 5. Condução do processo de coleta de dados & 0 & 1 & 0 & 2 & 0 & 1 & 3 & 14 & 0 & 15 & 299 \\
\hline 6. Arquivo dos dados & 0 & 1 & 1 & 2 & 1 & 5 & 1 & 10 & 2 & 13 & 283 \\
\hline 7. Sistematização e análise dos dados & 0 & 2 & 2 & 1 & 0 & 3 & 5 & 10 & 4 & 9 & 273 \\
\hline 8. Interpretação e discussão dos resultados & 0 & 2 & 1 & 2 & 0 & 3 & 3 & 12 & 3 & 10 & 277 \\
\hline 9. Divulgação pública à comunidade científica & 0 & 1 & 0 & 2 & 1 & 0 & 3 & 14 & 6 & 9 & 292 \\
\hline 10. Divulgação ao público em geral & 0 & 1 & 0 & 2 & 1 & 0 & 3 & 13 & 6 & 10 & 294 \\
\hline
\end{tabular}

Fonte: Os autores com base nas respostas ao questionário.

${ }^{10}$ Total ponderado.

Práxis Educativa, Ponta Grossa, v. 16, e2115213, p. 1-20, 2021

Disponível em: < https://www.revistas2.uepg.br/index.php/praxiseducativa> 
Com base na Tabela 1, nota-se que, das dez etapas do processo de pesquisa listadas, apenas a revisão da literatura foi pontuada pelos respondentes na primeira metade da escala (20 de 36 respondentes assim pontuaram), e a escolha do tema da pesquisa foi pontuada na primeira metade da tabela por metade dos respondentes. Enquanto as outras oito etapas foram todas avaliadas na segunda metade da escala, evidenciando a opinião no sentido da importância dos cuidados éticos ao longo de todo o processo de pesquisa, em quase todas as suas etapas. Também é interessante notar que o maior número de respondentes na segunda metade da escala é observado na condução do processo de coleta de dados (33 de 36) e nas etapas de divulgação da pesquisa à comunidade científica e ao público em geral (para cada uma, 32 de 30). Os dados trazidos pela pergunta [22] são indicativos de um elevado senso de valorização dos aspectos éticos da pesquisa por parte dos respondentes.

Tais dados foram confirmados nas respostas à pergunta [24], que convidou os respondentes a comentarem livremente sobre o tema do questionário, Formaşão, ética e pesquisa em Psicologia e Educação, deixando clara a opinião pessoal acerca da relação entre os três aspectos. Embora o significativo percentual de $33 \%$ que optaram por não responder, houve respostas muito interessantes para o objetivo da presente pesquisa, no sentido de uma preocupação com a ética, como dimensão de responsabilidade e de cuidado a cargo do próprio sujeito e produzida pela formação:

Considero muito importante que se desenvolva uma maior discussão destas questões éticas em investigações de cariz longitudinal e que envolvam multinformantes cujas respostas necessitam de ser emparelhadas através de código (Doutorando em Psicologia 2, 2019).

Acho importante que questões deontológicas sejam constantemente discutidas em aulas. Orientadores também deve abordar a questão com os orientandos (Doutorando em Psicologia 3, 2019).

A formação assume um papel de extrema importância quando se pretende efetuar uma investigação na área da Educação, uma vez que, mesmo que tenhamos já alguma informação sobre questões de ética e dos cuidados a ter uma vez quando estamos a observar e analisar de comportamentos de pessoas a orientação e supervisão de pessoas mais experientes, é sempre uma mais valia e permite aos jovens investigadores terem em conta aspetos que poderiam não ser considerados (Doutorando em Educação 17, 2019).

Essas respostas valorizam o aspecto dialogal, fundamental à esfera ética e à formação em geral, e, para a sua realização, a autonomia dos pesquisadores é requisito essencial.

Para concluir a análise do terceiro bloco do questionário (perguntas [16] a [24]), apesar de algumas respostas reconheceram e valorizarem a dimensão ética para além da mera normatização, é possível afirmar uma significativa concentração de expectativa na normatização e nos processos burocráticos levados a efeito pelas comissões de ética.

\section{Considerações finais}

Com base na análise hermenêutica objetiva das respostas ao questionário e com fundamento na literatura colacionada, é possível afirmar que a pesquisa nas CHS em Portugal também é afetada pelo movimento regulatório de caráter internacional, tal qual ocorre no Brasil. Foi possível perceber também que, em ambos os países, se afigura como fundamental o fortalecimento do aspecto ético na formação em pesquisa como parte inerente e indissociável da atividade. Nessa linha, a adoção de medidas que valorizem a formação (continuada) dos pesquisadores e a sua autonomia são mais compatíveis com a ética que sempre marcou a pesquisa nas CHS do que a mera proliferação de instâncias de controle.

Práxis Educativa, Ponta Grossa, v. 16, e2115213, p. 1-20, 2021

Disponível em: < https://www.revistas2.uepg.br/index.php/praxiseducativa> 
Apesar disso, o modelo português de regulação da conduta em pesquisa das CHS possui características que contribuem para pensar o caso brasileiro, nomeadamente o grau de intervenção das quatro esferas protagonistas do sistema: (1) o próprio pesquisador, (2) a instituição na qual a pesquisa é realizada, (3) a entidade representativa da área principal da pesquisa e (4) as influências externas. Ainda que distante da desejável autonomia do pesquisador no desenho e na condução do seu projeto, percebe-se, no modelo português, uma relação mais equilibrada entre os diferentes atores do processo: (1) com normas específicas, que respeitam o capital acumulado em pesquisa nas diferentes áreas das CHS; e (2) com um maior protagonismo das entidades nas quais a pesquisa é realizada. Essas características evidenciam um caráter mais descentralizado do dispositivo regulador, tão necessário para repensarmos o centralizado modelo brasileiro, concentrado no Ministério da Saúde.

Por fim, é importante pontuar que o presente artigo não tem como objetivo condenar de todo a regulação, apenas devolvê-la ao seu lugar e às suas possibilidades. Nesse sentido, merece registro que, em todas as diversas etapas desta pesquisa, a maioria das respostas analisadas fazem crer na disposição moral, comprometimento e capacidade intelectual dos pesquisadores respondentes para atuarem como agentes da transformação de um modelo burocrático para outro melhor, baseado fundamentalmente na capacidade de julgamento moral do pesquisador. A oportunidade de superação desse movimento de proliferação de instâncias de controle por um modelo fundamentado na verdadeira (e única) ética reside justamente na adequada formação dos pesquisadores ao longo de todas as etapas da sua carreira científica.

\section{Referências}

ALLEA. All European Academies. Código Europeu de Conduta para a Integridade da Investigação. ed. rev. Berlim: ALLEA, 2018. Disponível em: https://allea.org/wpcontent/uploads/2018/11/ALLEA-European-Code-of-Conduct-for-Research-Integrity-2017Digital_PT.pdf. Acesso em: 29 jan. 2020.

AMADO, J.; BOAVIDA, J. A afirmação social das Ciências da Educação: uma perspectiva histórica a partir de Portugal. Revista Educação em Questão, Natal, v. 32, n. 18, p. 7-39, maio/ago. 2008.

ANPED. Associação Nacional de Pós-Graduação e Pesquisa em Educação. Ética e pesquisa em Educação: subsídios. Volume 1. Rio de Janeiro: ANPEd, 2019. Disponível em: http://www.anped.org.br/etica-na-pesquisa/textos-e-videos\&gt. Acesso em: 20 maio 2019.

BRASIL. Resolução CNS No 196, de 10 de outubro de 1996. O Plenário do Conselho Nacional de Saúde em sua Quinquagésima Nona Reunião Ordinária, realizada nos dias 09 e 10 de outubro de 1996, no uso de suas competências regimentais e atribuições conferidas pela Lei $n^{\circ}$ 8.080, de 19 de setembro de 1990, e pela Lei $\mathrm{n}^{\circ}$ 8.142, de 28 de dezembro de 1990, resolve [...]. Brasília: Ministério da Saúde, Conselho Nacional de Saúde, [1996]. Disponível em: http://bvsms.saude.gov.br/bvs/saudelegis/cns/1996/res0196_10_10_1996.html\#: :text=Esta $\% 20$ Resolu $\%$ C3 $\%$ A7 $\%$ C3 $\%$ A30 $\% 20$ incorpora $\% 2 C \% 20$ sob $\% 20$ a,da $\% 20$ pesquisa $\% 20 \mathrm{e} \% 20 \mathrm{ao} \% 2$ 0Estado. Acesso em: 6 out 2020.

BRASIL. Resolução No 466, de 12 de dezembro de 2012. Aprova as diretrizes e normas regulamentadoras de pesquisas envolvendo seres humanos. Diário Oficial da União: seção 1, Brasilia, DF, n. 12, p. 59-62, 13 jun. 2013. 
BRASIL. Resolução No 510, de 7 de abril de 2016. Dispõe sobre as normas aplicáveis a pesquisas em Ciências Humanas e Sociais. Diário Oficial da União: seção 1, Brasília, DF, n. 98, seção 1, p. 44-46, 24 maio 2016.

CARVALHO, I. C. M.; MACHADO, F. V. A regulação da pesquisa e o campo biomédico: considerações sobre um debate epistêmico desde o campo da educação. Práxis Educativa, Ponta Grossa, v. 9, n. 1, p. 209-234, jan./jul. 2014. DOI: http://dx.doi.org/10.5212/PraxEduc.v.9i1.0010

CARVALHO, I. C. M. Ética e pesquisa em educação: o necessário diálogo internacional. Práxis Educativa, Ponta Grossa, v. 13, n. 1, p. 154-163, jan./abr. 2018. DOI: http://dx.doi.org/10.5212/PraxEduc.v.13i1.0009

CHAUÍ, M. A universidade operacional. Avaliação: Revista da Avaliação da Educação Superior, Sorocaba, v. 4, n. 3, suplem. 1, p. 3-8, 1999.

DE LA FARE, M.; CARVALHO, I. C. M.; PEREIRA, M. V. Ética e pesquisa em educação: entre a regulação e a potencialidade reflexiva da formação. Educação, Porto Alegre, v. 40, n. 2, p. 192 202, maio/ago. 2017. DOI: https://doi.org/10.15448/1981-2582.2017.2.27603

DE LA FARE, M.; SAVI NETO, P. A regulação da conduta dos pesquisadores na ciência brasileira: um problema de pesquisa ou um problema para a pesquisa em Educação? Práxis Educativa, Ponta Grossa, v. 14, n. 1, p. 319-332, jan./abr. 2019. DOI: https://doi.org/10.5212/PraxEduc.v.14n1.017

DUARTE, L. F. D. A ética em pesquisa nas Ciências Humanas e o imperialismo bioético no Brasil. Revista Brasileira de Sociologia, Brasília, v. 3, n. 5, p. 31-52, jan./jun. 2015. DOI: http://dx.doi.org/10.20336/rbs.90

DUARTE, L. F. D. Cronologia da luta pela regulação específica para as Ciências Humanas e Sociais da avaliação da ética em pesquisa no Brasil. Práxis Educativa, Ponta Grossa, v. 12, n. 1, p. $267-$ 286, jan./abr. 2017. DOI: http://dx.doi.org/10.5212/PraxEduc.v.12i1.0015

EDLER, F. A Húbris Bioética: rumo a uma polícia epistemológica? Revista Brasileira de Sociologia, Brasília, v. 3, n. 5, p. 95-113, jan./jun. 2015. DOI: https://doi.org/10.20336/rbs.95

EUROPEAN CHARTER FOR RESEARCHERS ETHICAL PRINCIPLES. Commission Recommendation of 11 March 2005 on the European Charter for Researchers and on a Code of Conduct for the Recruitment of Researchers. Official Journal of the European Union, 22 mar. $2005 . \quad$ Disponível em: https://eurlex.europa.eu/LexUriServ/LexUriServ.do?uri=OJ:L:2005:075:0067:0077:EN:PDF. Acesso em: 6 out. 2020.

FERNANDES, L. Ética da investigação na sociedade da transparência. In: NASCIMENTO, I.; SAVI NETO, P. (coord.). Ensaios sobre Ética e Investigação em Psicologia e em Educação. Porto: Legis Editora, 2020. p. 37-47.

FRADA, M. C. Entre a Ética e o Direito: por um código de conduta ética para a Universidade. In: SEQUEIROS, J. (ed.). Universidade, Ciência e Sociedade: desafios e fronteiras éticas. Porto: Universidade do Porto, 2014. p. 143-150.

GUILLEMIN, M.; GILLAM, L. Ethics, reflexivity, and "ethically important moments" in research. Qualitative Inquiry, v. 10, n. 2, p. 261-280, 2004. DOI: https://doi.org/10.1177/1077800403262360 
ISRAEL, M.; HAY, I. Research Ethics for Social Scientists: Between ethical conduct and regulatory compliance. Londres: Sage, 2006.

JORGE, M. M. A. Ciência e Ética: o projeto sonhado pelos pais fundadores e os seus limites. In: SEQUEIROS, J. (ed.). Universidade, Ciência e Sociedade: desafios e fronteiras éticas. Porto: Universidade do Porto, 2014a. p. 17-27.

JORGE, M. M. A. Competição ou cooperação na Universidade: algumas reflexões (2). In: SEQUEIROS, J. (ed.). Universidade, Ciência e Sociedade: desafios e fronteiras éticas. Porto: Universidade do Porto, 2014b. p. 35-39.

KAFKA, F. O processo. Tradução Álvaro Gonçalves. Lisboa: Círculo de Leitores, 1976.

LUNT, I. The Implications of the "Bologna Process" for the development of a European Qualification in Psychology. European Psychology, v. 10, p. 86-92, 2005. DOI: https://doi.org/10.1027/1016-9040.10.2.86

MAGALHÃES, J. Apontamento sobre a História da Faculdade de Psicologia e de Ciências da Educação da Universidade de Lisboa. In: MATOS, S. C.; JORGE, R. DO Ó. (coord.). A Universidade de Lisboa, Séculos XIX-XX - Volume II. Lisboa: Tinta-da-China, 2013. p. 10871105. Disponível em: https://repositorio.ul.pt/bitstream/10451/10461/1/históriaFPCE-UL.pdf. Acesso em: 23 abr. 2020.

MAINARDES, J. Seção temática: Ética na Pesquisa: Apresentação. Práxis Educativa, Ponta Grossa, v. 9, n. 1, p. 197-198, jan./jun. 2014. DOI: http://dx.doi.org/10.5212/PraxEduc.v.9i1

MAINARDES, J. A ética na pesquisa em Educação: desafios atuais. In: CARVALHO, M. V. C. de; CARVAlHedo, J. L. P.; ARAUjO, F. A. M. (org.). Caminhos da Pós-Graduacão em Educacão no Nordeste do Brasil: avaliacão, financiamento, redes e produção científica. Teresina: EDUFPI, 2016, p. 73-82. Disponível em: https://www.researchgate.net/profile/Jefferson_Mainardes. Acesso em: 20 nov. 2018.

MAINARDES, J. A ética na pesquisa em educação: panorama e desafios pós-Resolução CNS No510/2016. Educação, Porto Alegre, v. 40, n. 2, p. 160-173, maio/ago. 2017. DOI: http://dx.doi.org/10.15448/1981-2582.2017.2.26878

MANGETH, A. L. G. Análise comparativa entre os princípios informadores do regulamento geral de proteção de dados da união europeia e as normas do direito brasileiro. 2018. Disponível em: http://www.pucrio.br/pibic/relatorio_resumo2018/relatorios_pdf/ccs/DIR/DIR-Ana\%20Lara \%20

Galhano\%20M. Acesso em: 29 jan. 2020.

MENDES, S. A. et al. A study of the ethical dilemmas experienced by school psychologists in Portugal. Ethics \& Behavior, v. 26, p. 395-414, 2016. DOI: http://dx.doi.org/10.1080/10508422.2015.1029047

PEIXOTO, P. Ética e regulação da pesquisa nas Ciências Sociais na sociedade do consentimento. Educação, Porto Alegre, v. 40, n. 2, p. 150-159, 2017. DOI: https://doi.org/10.15448/1981$\underline{\text { 2582.2017.2.27005 }}$

PEIXOTO, P. et al. Políticas institucionais, em Portugal, relativas à fraude académica. In: PEIXOTO, P. et al. (coord.). Fraude e plágio na Universidade: a urgência de uma cultura de 
integridade no Ensino Superior. Coimbra: Imprensa da Universidade de Coimbra, 2016. DOI: http://dx.doi.org/10.14195/978-989-26-1123-5

PELS, P. Professions of duplexity: a prehistory of ethical codes in anthropology. Current Anthropology, v. 40, n. 2, p. 101-136, 1999. DOI: http://dx.doi.org/10.1086/200001

RORIZ, M.; PADEZ, C. A regulação ética da investigação e os desafios postos às práticas etnográficas, Etnográfica, Lisboa, v. 21, n. 1, p. 75-95, 2017. DOI: https://doi.org/10.4000/etnografica.4820

PORTUGAL. Decreto-Lei $\mathbf{N}^{\circ} \mathbf{7 4}$, de 24 de março de 2006. Aprova o regime jurídico dos graus e diplomas do ensino superior, em desenvolvimento do disposto nos artigos $13 .^{\circ}$ a $15 .^{\circ}$ da Lei n. ${ }^{\circ}$ 46/86, de 14 de Outubro (Lei de Bases do Sistema Educativo), bem como o disposto no n. ${ }^{\circ} 4$ do artigo $16 .^{\circ}$ da Lei n. ${ }^{\circ} 37 / 2003$, de 22 de Agosto (estabelece as bases do financiamento do ensino superior). Lisboa: Diário da República Eletrônico, [2016]. Disponível em: shorturl.at/gvLM0. Acesso em: 6 out. 2020.

PORTUGAL. Decreto-Lei $\mathbf{N}^{\circ}$ 79, de 14 de maio de 2014. Aprova o regime jurídico da habilitação profissional para a docência na educação pré-escolar e nos ensinos básico e secundário. Lisboa: Diário da República Eletrônico, [2014a]. Disponível em: https://dre.pt/pesquisa//search/25344769/details/maximized. Acesso em: 6 out. 2020.

PORTUGAL. Declaração de Retificação No 32, de 27 de junho 2014. Retifica o Decreto-Lei n. ${ }^{\circ} 79 / 2014$ de 14 de maio, do Ministério da Educação e Ciência que aprova o regime jurídico da habilitação profissional para a docência na educação pré escolar e nos ensinos básico e secundário, publicado no Diário da República n. ${ }^{\circ}$ 92, 1. a série, de 14 de maio. Lisboa: Diário da República Eletrônico, [2014b]. Disponível em: https://dre.pt/pesquisa//search/25345633/details/maximized. Acesso em: 6 out. 2020.

SANTOS, L. A. C.; JEOLÁS, L. Uma Comissão Nacional de Ética na Pesquisa, as Ciências Biomédicas e as Ciências Humanas: trespassing à brasileira. Revista Brasileira de Sociologia, Brasília, v. 3, n. 5, p. 239-259, jan./jun. 2015. DOI: http://dx.doi.org/10.20336/rbs.102

SANTOS, L. H. S.; KARNOPP, L. B. (org.). Ética e pesquisa em Educação: questões e proposições às ciências humanas e sociais. Porto Alegre: UFRGS, 2017.

SARTI, C. A ética em pesquisa transfigurada em campo de poder: notas sobre o sistema CEP/Conep. Revista Brasileira de Sociologia, Porto Alegre, v. 3, n. 5, p. 79-96, jan./jun. 2015. DOI: http://dx.doi.org/10.20336/rbs.94

SAVI NETO, P. A atualidade da crítica de Adorno para as pesquisas qualitativas com bases empíricas em educação. Veritas, Porto Alegre, v. 63, n. 2, p. 744-764, 2018. DOI: https://doi.org/10.15448/1984-6746.2018.2.30792

SAVI NETO, P; DE LA FARE, M. Regulação da pesquisa em Educação: tensões entre autonomia ética e heteronomia normativa. Educação \& Sociedade, Campinas, v. 40, e0191340, 2019. DOI: https://doi.org/10.15448/1984-6746.2018.2.30792

SAVI NETO, P.; DE LA FARE, M; SILVA, D. S. da. Ética, autonomia e pesquisa em educação: questionamentos à regulação brasileira da conduta dos pesquisadores. Revista Brasileira de Educação, v. 25, e250013, 2020. DOI: http://dx.doi.org/10.1590/S1413-24782020250013 
SHORE, C.; WRIGHT, S. Audit culture and anthropology: neo-liberalism in British higher education. Journal of the Royal Anthropological Institute, v. 5, n, 4, p. 557-576, dez. 1999. DOI: https://doi.org/10.2307/2661148

SILVA, S. Doutoramentos nos politécnicos vão mesmo avançar. E nasceu um Simplex para a ciência. Público, Lisboa, 28 jun. 2018. (Ensino Superior). Disponível em: https://www.publico.pt/2018/06/28/sociedade/noticia/doutoramentos-nos-politecnicos-vaoavancar-1836195. Acesso em: 24 dez. 2019.

SOBOTTKA, E. A. Regulamentação, ética e controle social na pesquisa em Ciências Humanas. Revista Brasileira de Sociologia, Brasília, v. 3, n. 5, p. 51-77, jan./jun. 2015. DOI: http://dx.doi.org/10.20336/rbs.93

VILELA, R. A. T. A análise sociológica "Hermenêutica Objetiva" - novas perspectivas na pesquisa qualitativa. In: REUNIÃO ANUAL DA ANPED, 31., 2011, Caxambu. Anais eletrônicos [...]. Caxambu: ANPEd, 2011. Disponível em: http://31 reuniao.anped.org.br/1trabalho/gt14-4741-int.pdf. Acesso em: 15 abr. 2018.

VILELA, R. A. T. A presença da Teoria Crítica no debate e na pesquisa educacional no Brasil e na Alemanha no período de 1995 à atualidade. Relatório de Pesquisa, CNPq 2006- 2008. PUCMinas, 2009. Disponível em: www.ich.ped/pucminas.br. Acesso em: 5 abr. 2018.

VILELA, R. A. T; NOACK-NAPOLES, J. "Hermenêutica Objetiva" e sua apropriação na pesquisa empírica na área da Educação. Linhas Críticas, Brasília, v. 16, n. 31, p. 305-326, jul./dez. 2010. DOI: https://doi.org/10.26512/lc.v16i31.3618

ZALUAR, A. Ética na pesquisa social: novos impasses burocráticos e paroquiais. Revista Brasileira de Sociologia, Brasília, v. 3, n. 5, p. 133-157, jan./jun. 2015. DOI: http://dx.doi.org/10.20336/rbs.97

Recebido em 15/06/2020

Versão corrigida recebida em 28/09/2020

Aceito em 30/09/2020

Publicado online em 21/10/2020

Práxis Educativa, Ponta Grossa, v. 16, e2115213, p. 1-20, 2021

Disponível em: < https://www.revistas2.uepg.br/index.php/praxiseducativa> 